\title{
Tissue gene mutation profiles in patients with colorectal cancer and their clinical implications
}

\author{
JUN YE ${ }^{1}$, MEI LIN ${ }^{1}$, CHUANMENG ZHANG $^{1}$, XIAOWEI ZHU ${ }^{1}$, SUMENG LI $^{1}$, \\ HUI LIU ${ }^{2}$, JIANFENG YIN ${ }^{3}$, HONG YU ${ }^{1}$ and KUICHUN ZHU ${ }^{4,5}$ \\ ${ }^{1}$ Taizhou People's Hospital, The Center for Translational Medicine, Taizhou, Jiangsu 225300; \\ ${ }^{2}$ Xuzhou Medical University, Department of Pathology, Xuzhou, Jiangsu 221000; \\ ${ }^{3}$ Jianwei Medical Laboratory, Taizhou, Jiangsu 225300; \\ ${ }^{4}$ R\&D Department, Labway Clinical Laboratories, Shanghai 210000; \\ ${ }^{5}$ R\&D Department, Wuxi Shenrui Bio-Pharmaceuticals Co., Ltd., \\ Wuxi, Jiangsu 214000, P.R. China
}

Received November 7, 2019; Accepted April 3, 2020

DOI: $10.3892 /$ br.2020.1303

\begin{abstract}
Colorectal cancer (CRC) is one of the most common types of cancer in the world, and targeted therapy is frequently used in the clinical management of the disease. A complete and accurate picture of tissue gene mutations is therefore critical. Tissue specimens from 117 patients with CRC were used for high throughput DNA next-generation sequencing (NGS) analysis. Hotspots from 50 genes frequently associated with the development and progression of solid tumors were targeted for sequencing. Characterization of tissue gene mutations was performed; the tissue mutation positive rates of KRAS, KIT, PIK3CA, MET and EGFR were 52.1, 19.7, 29.9, 15.4 and $14.5 \%$, respectively. The mutation positive rates of TP53, APC, CDKN2A, STK11 and FBXW7 were 65.8, 39.3, $32.5,19.7$ and $19.7 \%$, respectively. The most frequent $K R A S$ mutations were $\mathrm{G} 12 \mathrm{~A} / \mathrm{C} / \mathrm{D} / \mathrm{S} / \mathrm{V}$, accounting for $61.2 \%$ of all KRAS mutations. The most frequent TP53 mutations were $\mathrm{R} 273 \mathrm{C} / \mathrm{G} / \mathrm{H} / \mathrm{L}$, accounting for $8.5 \%$ of all TP53 mutations. The most frequent $A P C$ mutation was E1554fs, accounting for $19.7 \%$ of all APC mutations. IDH1 R132C/H, KIT M541L, MET $\mathrm{N} 375 \mathrm{~S}$, and $S M A D 4 \mathrm{R} 361 \mathrm{C} / \mathrm{H}$ were also frequently identified. TP53 mutations were more common in patients $\geq 60$ years old $(\mathrm{P}<0.05)$, and IDH1 mutations were more common in male patients $(\mathrm{P}<0.05)$. NGS 50 gene panel sequencing provides a
\end{abstract}

Correspondence to: Dr Kuichun Zhu, R\&D Department, Wuxi Shenrui Bio-Pharmaceuticals Co., Ltd., 1699 Huishan Boulevard, Wuxi, Jiangsu 214000, P.R. China

E-mail: kzhu68@hotmail.com

Dr Hong Yu, Taizhou People's Hospital, The Center for Translational Medicine, 399 South Hailing Road, Taizhou, Jiangsu 225300, P.R. China

E-mail: yuhongjianglin@163.com

Key words: colorectal cancer, gene mutation, targeted therapy, next-generation sequencing comprehensive tissue gene mutation profile which may significantly improve clinical management.

\section{Introduction}

Colorectal cancer (CRC) is the fourth most common type of cancer in terms of incidence and the third leading cause of cancer-associated death in the world (1). In the last decade the incidence and the mortality rates of CRC have decreased in the US and some European countries; however, both the incidence and the mortality rates of CRC in China have increased $(2,3)$. The yearly global burden of CRC is estimated to be 2.2 million new cases and 1.1 million deaths by 2030 (2).

The majority of cases of CRC cases are sporadic, and hereditary CRC accounts for $\sim 5 \%$. CRC is a heterogeneous disease, and several oncogenes and tumor suppressor genes, such as TP53, KRAS, APC and CDKN2A, are involved in its development (4-6). Gene mutations are the basis for selection of targeted agents for the treatment of various types of malignancy. There are targeted drugs, such as anti-EGFR agents and anti-VEGF/VEGFR agents, that are used in combination with surgery and chemotherapy $(4,7,8)$. Therefore, accurate identification of gene mutations in patients with CRC is critical for selecting therapeutic agents, and predicting efficacy and prognosis.

High throughput DNA sequencing (NGS) technology has been widely used in research as well as clinically. NGS provides sequencing data in quantities orders of magnitude higher than Sanger sequencing, and with much greater sensitivity (9). NGS has been used for detection of gene mutations in CRC using DNA from tissue sections, blood and stool (10-15). Pooling of large quantities of data of gene mutations from tumor tissues and determining their associations with the clinicopathological characteristics may provide important information regarding the pathogenesis of CRC, and thus novel approaches for clinical intervention. To further study the mutational spectrum, mutation hotspots of genes and their clinical associations in patients with CRC in a southeastern Chinese population, NGS 
panel sequencing of specimens from 117 patients diagnosed with CRC was performed, and the significance, genetics and associations with the clinicopathological data were assessed.

\section{Materials and methods}

Patients and specimen. All patients were hospitalized at Taizhou People's Hospital (Taizhou, China) between January 2011 and December 2013. Among the 117 patients enrolled, 78 patients were male, and 39 patients were female. The median age was 65 years old (range, 58-71). Diagnosis of CRC was performed independently by two pathologists based on histological examination. Sections of tumor tissues were sent to Beijing Genomics Institute (BGI) for NGS. The present study was approved by the Ethical Committee on Medical Research of the Taizhou People's Hospital. Written informed consent was obtained from all study subjects Tissue sections from 117 patients with CRC were analyzed using NGS. The clinicopathological data are summarized in Table SI. Tumor-Node-Metastasis staging was performed as reported previously (16). As in non-small cell lung cancer, patients with a low abundance of EGFR mutations may still benefit from EGFR inhibitors $(17,18)$, thus two cutoff values for tissue gene mutation abundances were used, 5 and $0.5 \%$. The objective was not to miss any mutations with a low prevalence, but still sufficient for beneficial results from targeted therapy.

$N G S$ and data analysis. Tissue sections were used for genomic DNA extraction using a kit from Amoy Diagnostics, Co., Ltd. according to the manufacturer's protocol. Only tumor cell-rich regions identified by pathologists were used for DNA extraction. NGS library construction and NGS were performed by BGI. The targeted gene regions were amplified by multiplex PCR using genomic DNA from tissue sections as the template and reagents from the Ion AmpliSeq ${ }^{\mathrm{TM}}$ Cancer Hotspot Panel v2 kit (Thermo Fisher Scientific, Inc.) according to the manufacturer's protocol. The amplified target regions were used for NGS library construction using the Fast cfDNA Library Prep Set for MGI kit (CoWin Biosciences) according to the manufacturer's protocol. NGS was performed on a MGISEQ-2000RS platform using the proprietary sequencing kit (BGI). Speedseq (version 0.1.2: Quinlan Lab) was used for data mapping, and hg19 was used as the human reference genome. Strelka (version 2.9.2; Illumina, Inc.) was used for variant calling. For all sequencing data, Q30 sequences were $>85 \%$. The average read depth was $10,000 x$. The minimal read depth for variant calling was $2,000 x$.

Statistical analysis. Differences between rates were compared using a $\chi^{2}$ test. Odds ratio (OR) analysis was performed using MedCalc (medcalc.org/calc/odds_ratio.php). $\mathrm{P}<0.05$ was considered to indicate a statistically significant difference. Population data from Chinese Millionome Database (db.cngb.org/cmdb/) were used for comparison.

\section{Results}

Mutation rates of common genes. Tissue gene mutation positive rates are summarized in Table I. KRAS, KIT, PIK3CA, $M E T$ and $E G F R$ were among the most frequently mutated
Table I. Mutation occurrence of genes in CRC.

A, Driver genes

\begin{tabular}{lccccc}
\hline & \multicolumn{2}{c}{$0.5 \%$ as cutoff } & & \multicolumn{2}{c}{$5 \%$ as cutoff } \\
\cline { 2 - 3 } \cline { 5 - 6 } Gene & $\begin{array}{c}\text { Positive } \\
\text { cases }\end{array}$ & $\begin{array}{c}\text { Positive } \\
\text { rate, } \%\end{array}$ & & $\begin{array}{c}\text { Positive } \\
\text { cases }\end{array}$ & $\begin{array}{c}\text { Positive } \\
\text { rate, } \%\end{array}$ \\
\hline KRAS & 61 & 52.1 & & 50 & 42.7 \\
KIT & 23 & 19.7 & & 11 & 9.4 \\
PIK3CA & 35 & 29.9 & & 19 & 16.2 \\
MET & 18 & 15.4 & & 10 & 8.5 \\
EGFR & 17 & 14.5 & & 1 & 0.9 \\
BRAF & 14 & 12 & & 6 & 5.1 \\
IDH1 & 14 & 12 & & 1 & 0.9 \\
PDGFR3 & 10 & 8.5 & & 0 & 0 \\
CTNNB1 & 8 & 6.8 & & 5 & 4.2 \\
IDH2 & 8 & 6.8 & & 0 & 0 \\
HER2 & 6 & 5.1 & & 1 & 0.9 \\
SMO & 6 & 5.1 & & 1 & 0.9 \\
\hline
\end{tabular}

B, Tumor suppressor genes

\begin{tabular}{lccccc}
\hline & \multicolumn{2}{c}{$0.5 \%$ as cutoff } & & \multicolumn{2}{c}{$5 \%$ as cutoff } \\
\cline { 2 - 3 } \cline { 6 - 7 } Gene & $\begin{array}{c}\text { Positive } \\
\text { cases }\end{array}$ & $\begin{array}{c}\text { Positive } \\
\text { rate, } \%\end{array}$ & & $\begin{array}{c}\text { Positive } \\
\text { cases }\end{array}$ & $\begin{array}{c}\text { Positive } \\
\text { rate, \% }\end{array}$ \\
\hline TP53 & 77 & 65.8 & & 56 & 47.9 \\
APC & 46 & 39.3 & & 34 & 29.1 \\
CDKN2A & 38 & 32.5 & & 1 & 0.9 \\
STK11 & 23 & 19.7 & & 11 & 9.4 \\
FBXW7 & 23 & 19.7 & & 8 & 6.8 \\
PTEN & 19 & 16.2 & & 2 & 1.7 \\
SMAD4 & 14 & 12 & & 3 & 2.6 \\
MLH1 & 12 & 10.3 & & 7 & 6 \\
VHL & 10 & 8.5 & & 2 & 1.7 \\
ATM & 9 & 7.7 & & 2 & 1.7 \\
RB1 & 7 & 6 & & 0 & 0 \\
HNF1A & 7 & 6 & & 0 & 0 \\
SMARCB1 & 6 & 5.1 & & 2 & 1.7 \\
\hline
\end{tabular}

driver genes, and TP53, APC, CDKN2A, STK11 and FBXW7 were the most frequently mutated tumor suppressor genes (Table I). For the majority of patients with KRAS, TP53 or $A P C$ mutations, the tissue mutation frequencies were $>5 \%$, and for the majority of patients with $E G F R, B R A F$ and $C D K N 2 A$ mutations, the tissue mutation frequencies were $<5 \%$ (Table I).

Mutation spectrum and hotspots. The mutation spectrum was analyzed, and the results are summarized in Tables II and III. IDH1 R132C/H, KIT M541L, KRAS G12A/C/D/S/V, MET $\mathrm{N} 375 \mathrm{~S}$ and $S M A D 4 \mathrm{R} 361 \mathrm{C} / \mathrm{H}$ were some of the more prominent mutation hotspots (Tables II and III). BRAF V600 mutations accounted for $40 \%$ of all BRAF mutations (Table III). 
Table II. Spectrum of mutations in tumor suppressor genes.

\begin{tabular}{|c|c|c|c|c|}
\hline Gene & Exon & Mutations & $\begin{array}{l}\text { Positive } \\
\text { cases, } \mathrm{n}\end{array}$ & $\begin{array}{c}\text { Relative } \\
\text { frequency }^{\mathrm{a}}(\%)\end{array}$ \\
\hline \multirow[t]{5}{*}{$A P C$} & \multirow[t]{5}{*}{ Exon16 } & E1554fs & 12 & 19.7 \\
\hline & & K1462fs & 5 & 8.2 \\
\hline & & Q886X & 5 & 8.2 \\
\hline & & $\mathrm{R} 876 \mathrm{X}$ & 5 & 8.2 \\
\hline & & Others & 34 & 55.7 \\
\hline \multirow[t]{6}{*}{$C D K N 2 A$} & \multirow[t]{6}{*}{ Exon2 } & D125N & 12 & 22.6 \\
\hline & & $\mathrm{R} 124 \mathrm{H}$ & 8 & 15.1 \\
\hline & & D108N & 6 & 11.3 \\
\hline & & V106M & 6 & 11.3 \\
\hline & & R128W & 5 & 9.4 \\
\hline & & Others & 16 & 30.2 \\
\hline \multirow[t]{4}{*}{$F B X W 7$} & Exon8 & $\mathrm{R} 385 \mathrm{C} / \mathrm{H}$ & 10 & 34.5 \\
\hline & Exon9 & R266C & 6 & 20.7 \\
\hline & Exon4 & R278X & 6 & 20.7 \\
\hline & Exon9 & Others & 7 & 24.1 \\
\hline \multirow[t]{2}{*}{ PTEN } & \multirow[t]{2}{*}{ Exon6 } & $\mathrm{R} 173 \mathrm{C} / \mathrm{H}$ & 5 & 26.3 \\
\hline & & Others & 14 & 73.7 \\
\hline \multirow[t]{2}{*}{ SMAD4 } & Exon9 & $\mathrm{R} 361 \mathrm{C} / \mathrm{H}^{\mathrm{b}}$ & 13 & 86.7 \\
\hline & Exon3 & A118V & 2 & 13.3 \\
\hline \multirow[t]{4}{*}{ STK11 } & Exon8 & F354L & 10 & 37 \\
\hline & Exon4 & D194N & 6 & 22.2 \\
\hline & Exon4 & E199K & 6 & 22.2 \\
\hline & Exon6 & Others & 5 & 18.5 \\
\hline \multirow[t]{7}{*}{ TP53 } & Exon4 & $\mathrm{R} 273 \mathrm{C} / \mathrm{G} / \mathrm{H} / \mathrm{L}$ & 19 & 8.5 \\
\hline & Exon1 & $\mathrm{R} 175 \mathrm{C} / \mathrm{H}$ & 14 & 6.3 \\
\hline & Exon2 & R213Q/X & 14 & 6.3 \\
\hline & Exon3 & R248Q/W & 12 & 5.4 \\
\hline & Exon2 & R196Q/X & 11 & 4.9 \\
\hline & \multirow[t]{2}{*}{ Exon4 } & R280S & 11 & 4.9 \\
\hline & & Others & 143 & 63.8 \\
\hline
\end{tabular}

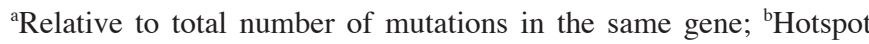
mutation.

Common synonymous variants. HRAS H27H (rs12628) and PDGFRA V824V (rs2228230) are synonymous variants, but were present in patients with CRC at high frequencies. The variant rate of $H R A S \mathrm{H} 27 \mathrm{H}$ in CRC patients was 90/117 (76.9\%; OR 5.206, $\mathrm{P}<0.001$. The OR for PDGFRA V824V was 1.310 , but this was not statistically significant (Table IV).

Associations between gene mutations and clinicopathological data. Clinicopathological data and their associations with gene mutations were assessed. The majority of patients in the present study were $\geq 60$ years, and TP53 mutations were more frequent in patients $>60$ years old $(\mathrm{P}<0.05$, Table $\mathrm{V})$. The majority of patients in the study were male, and IDHI mutations were more frequent in male patients $(\mathrm{P}<0.05$, Table V). Patients with earlier stages of cancer (TNM stages I and stage II) more frequently had a cancer of the rectum as opposed to the colon $(\mathrm{P}<0.05$, Table V). Advanced TNM stage (stage IV) was associated with
Table III. Spectrum of mutations in driver genes.

\begin{tabular}{|c|c|c|c|c|}
\hline Gene & Exon & Mutations & $\begin{array}{l}\text { Positive } \\
\text { cases, } \mathrm{n}\end{array}$ & $\begin{array}{c}\text { Relative } \\
\text { frequency }(\%)\end{array}$ \\
\hline \multirow[t]{2}{*}{$B R A F$} & exon15 & p.V600E/M & 6 & 40 \\
\hline & & Others & 9 & 60 \\
\hline \multirow[t]{4}{*}{$E G F R$} & Exon19 & p.A743T & 5 & 22.7 \\
\hline & Exon18 & p.G721S & 4 & 18.2 \\
\hline & Exon19 & p.746del & 3 & 13.6 \\
\hline & & Others & 10 & 45.5 \\
\hline \multirow[t]{2}{*}{ IDHI } & Exon4 & p.R132C/H & 13 & 86.7 \\
\hline & & Others & 2 & 13.3 \\
\hline \multirow[t]{2}{*}{$K I T$} & Exon 10 & p.M541L ${ }^{b}$ & 19 & 79.2 \\
\hline & & Others & 5 & 20.8 \\
\hline \multirow[t]{4}{*}{$K R A S$} & Exon2 & p.G12A/C/D/s & $/ \mathrm{V}^{\mathrm{b}} 41$ & 61.2 \\
\hline & Exon2 & p.G13D & 13 & 19.4 \\
\hline & Exon4 & p.A146T & 5 & 7.5 \\
\hline & Exon $2 / 3$ & Others & 8 & 11.9 \\
\hline \multirow[t]{2}{*}{$M E T$} & Exon2 & p.N375S ${ }^{b}$ & 17 & 94.4 \\
\hline & Exon14 & p.R988C & 1 & 5.6 \\
\hline \multirow[t]{5}{*}{$P I K 3 C A$} & Exon10 & p.E545G/K & 12 & 27.9 \\
\hline & Exon21 & p.H1047L/R & 8 & 18.6 \\
\hline & Exon21 & p.R1023Q & 8 & 18.6 \\
\hline & Exon2 & p.R88Q & 6 & 14 \\
\hline & & Others & 9 & 20.9 \\
\hline
\end{tabular}

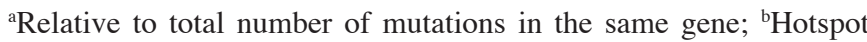
mutation.

an increased rate of lymph node metastasis $(\mathrm{P}<0.05$, Table V). There were no other significant associations observed. Gene mutation data are summarized in Table SII.

\section{Discussion}

Accurate identification of gene mutations in CRC is critical for selecting the optimum therapeutic agents, and for predicting efficacy and prognosis. The accumulation of gene mutation data also provides important information regarding the pathogenesis of the disease and sheds light on potential novel approaches for clinical management (19-22). NGS covers considerably more genes and for much larger sequencing regions, allowing for greater sequencing sensitivity compared with Sanger sequencin or PCR tests. NGS panel studies also have the advantage of sequencing hot spot regions of a few dozen to a few hundred genes with established implications in clinical diagnosis or targeted therapy, whilst maintaining high sequencing depth compared with whole exome sequencing or whole genome sequencing. Higher sequencing depths translates to higher detection sensitivity and reliability. In CRC studies, panels of 22-genes and 50-genes are commonly used $(11,23)$.

$K R A S$ and NRAS mutation tests are mandatory for antiEGFR therapy (Cetuximab, Panitumumab) (24). KRAS, BRAF and $P I K 3 C A$ mutation tests are useful for predicting the efficacy of anti-EGFR agents and anti-angiogenic agents (Aflibercept, 
Table IV. Frequent synonymous variants identified in the patients with colorectal cancer.

\begin{tabular}{lllllr}
\hline Gene & Variant & \multicolumn{1}{c}{ SNP } & Variant rate & OR $^{\mathrm{b}}$ & 95\% CI \\
\hline HRAS & p.H27H & rs 12628 & $90 / 117$ & 5.206 & $3.369-8.044$ \\
PDGFRA & p.V824V & rs2228230 & $36 / 117$ & 1.31 & $0.882-1.947$ \\
\hline
\end{tabular}

$\mathrm{P}<0.05,{ }^{\mathrm{a}} \mathrm{P}<0.001 .{ }^{\mathrm{b}} \mathrm{Based}$ on the highest possible estimated variant rate in the population from the Chinese Millionome Database CMDB.

Table V. Associations between clinicopathological data and gene mutation data.

\begin{tabular}{lccc}
\hline Group & Cases (\%) & Association with & Associations \\
\hline Age & & TP53 mutation & \\
$14-59$ & $36(31.03 \%)$ & & 13 \\
$\geq 60$ & $80(68.97 \%)$ & & $64^{\mathrm{a}}$ \\
Sex & & IDH1 mutation & \\
Male & $78(66.67 \%)$ & & $13^{\mathrm{a}}$ \\
Female & $39(33.33 \%)$ & & 1 \\
Location & & TNM I/II stage & $13^{\mathrm{a}}$ \\
Rectum & $63(53.85)$ & & 1 \\
Colon & $54(46.15 \%)$ & & 11 \\
TNM stage & & & $42^{\mathrm{a}}$ \\
I/II/III & $42(36.21 \%)$ & LN metastasis & \\
IV & $74(63.79 \%)$ & & \\
\hline
\end{tabular}

${ }^{\mathrm{a}} \mathrm{P}<0.05$. TNM, Tumor-Node-Metastasis staging system.

Bevacizumab, Ramucirumab, Regorafenib) (7,8,25). BRAF inhibitor Dabrafenib and MEK inhibitor Trametinib were used to treat patients with CRC who harbored a $B R A F$ V600E mutation, and achieved positive results (26). In the present study, $12 \%$ of patients harbored $B R A F$ mutations, and $40 \%$ of $B R A F$ mutations were V600 mutations. PIK3CA gene encodes a PI3K catalytic subunit. The efficacy of PI3K inhibitors and mTOR inhibitors, approved for treatment of certain types of cancer or are in clinical trials, has yet to be assessed in patients with CRC (27). Regorafenib is an inhibitor of multiple tyrosine kinases, including BRAF, KIT, VEGFR and PDGFR, and used for the treatment of patients with metastatic CRC (28-30). MET N375S was found as a hotspot of mutations in the present study. The mutation may confer resistance to MET inhibition (31). The treatment of patients with CRC with MET inhibitors has yet to show promising results (32). Furthermore, MET mutations and amplifications may result in resistance to anti-EGFR and anti-BRAF therapy (33). IDHI $\mathrm{R} 132 \mathrm{C} / \mathrm{H}$ were also mutation hotspots in the present study. The IDH1 inhibitor Ivosidenib achieved promising results in the treatment of patients with acute leukemia carrying IDHI mutations (34). However, there are no reports regarding the use of this agent in CRC in clinical trials, to the best of our knowledge. HER 2 mutations, such as L755S and V842I, may activate the HER2 kinase domain. Mutant HER2 may sensitize CRC towards Trastuzumab and irreversible HER inhibition (Aftinib,
Neratinib, or Dacomitinib) (35). All the 6 cases with HER2 mutations in the present study carried a V842I mutation.

TP53 gene mutations are frequently identified in solid tumors including CRC (36), and in the present study $65.8 \%$ of patients with CRC harbored TP53 mutations. APR-246 was designed to restore the function of mutant p53 (37). There are multiple ongoing clinical trials involving APR-246 in melanoma, ovarian cancer and hematological malignancies, but not in CRC as of yet, although the agent was shown to exhibit anti-tumor effects on CRC cells in vitro (38). Mutant APC or CTNNB1 activates the WNT/ $\beta$-catenin signaling pathway and multiple agents targeting this pathway are in clinical trials for treatment of various types of cancer, including CRC (39). Although germline mutations in $C D K N 2 A$ increase an individual's susceptibility to CRC $(40,41)$, in the present study, the mutation abundance was $<5 \%$ in most cases, indicative of the somatic nature. The gene product of $C D K N 2 A$ or p16 protein acts as an inhibitor of CDK4, and $C D K N 2 A$ mutations are common in tumors (42). Clinical trials with CDK4 inhibitor Abemaciclib or Palbociclib in solid tumors including CRC achieved some positive results $(43,44)$. Mutations in $F B X W 7$ were also commonly identified in the present study. The $F B X W 7$ mutations are a negative prognostic factor for metastatic CRC (45).

The 50-gene panel used in the present study also covers certain causative genes for common hereditary CRC syndromes, such as $A P C$ for familial adenomatous polyposis, MLH1 for Lynch syndrome, PTEN for Cowden syndrome, SMAD4 for Juvenile polyposis syndrome, and STK11 for Peutz-Jeghers syndrome (46-48). A common characteristic of these syndromes is early-onset CRC $(46,47)$. The tissue mutation frequencies of PTEN, SMAD4 and STK 11 genes in most cases were $<5 \%$ in the present study, indicative of the somatic nature of these mutations. When a certain hereditary CRC syndrome is suspected based on clinical manifestations or NGS screening data, verification by Sanger sequencing using DNA from the peripheral blood is recommended. $M L H 1$ is the most common gene of mismatch repair genes that are involved in microsatellite instability, that is present in up to $15 \%$ of patients with CRC. $M L H 1$ mutation and microsatellite instability provide important guides for CRC chemotherapy and immunotherapy in clinical settings $(49,50)$.

NGS 50-gene panel sequencing provides comprehensive tissue gene mutation profiles. For most patients with CRC, one or several gene mutations are identified. In the present study, novel mutation spectrums and hotspots of genes commonly involved in CRC were identified, as well as some tentative and potentially relevant associations between genotypes and phenotypes. Further studies are required to investigate the 
associations between gene variants in tumor tissues and gene variants identified through liquid biopsy, with an expanded gene panel, with an emphasis on biomarkers for immunotherapy. Mutations of driver genes or tumor suppressor genes may provide critical information for target gene therapy as well as prognosis. A thorough understanding of the significance of the gene mutations is important in the clinical management of patients with CRC.

\section{Acknowledgements}

Not applicable.

\section{Funding}

The work was funded in part by the 333 Plan Foundation of Jiangsu (grant no. BRA2017173), the Taizhou People's Hospital Medical Innovation Team Foundation (grant nos.CXTDA201904 and CXTDA201901), and the 2018 Taizhou People's Hospital Mandatory Project (grant no. ZL201733).

\section{Availability of data and materials}

The datasets used and/or analyzed in the present study are available from the corresponding author on reasonable request.

\section{Authors' contributions}

JY, ML, HY, KZ conceived and designed the project. CZ, XZ, SL, HL performed collection and quality control of clinical information, specimens and tissue sections. JY assisted with specimen processing and data collection. $\mathrm{KZ}$ analyzed the data and prepared the manuscript. All authors read and approved the final manuscript.

\section{Ethics approval and consent to participate}

The present study was approved by the Ethics Committee of Taizhou People's Hospital (Taizhou, China). All subjects provided informed consent to participate in the study.

\section{Patient consent for publication}

Not applicable.

\section{Competing interests}

The authors declare that they have no competing interests.

\section{References}

1. Bray F, Ferlay J, Soerjomataram I, Siegel RL, Torre LA and Jemal A: Global cancer statistics 2018: GLOBOCAN estimates of incidence and mortality worldwide for 36 cancers in 185 countries. CA Cancer J Clin 68: 394-424, 2018.

2. Arnold M, Sierra MS, Laversanne M, Soerjomataram I, Jemal A and Bray F: Global patterns and trends in colorectal cancer incidence and mortality. Gut 66: 683-691, 2017.

3. Zhu J, Tan Z, Hollis-Hansen K, Zhang Y, Yu C and Li Y: Epidemiological trends in colorectal cancer in China: An ecological study. Dig Dis Sci 62: 235-243, 2017.
4. Rodriguez-Salas N, Dominguez G, Barderas R, Mendiola M, García-Albéniz X, Maurel J and Batlle JF: Clinical relevance of colorectal cancer molecular subtypes. Crit Rev Oncol Hematol 109: 9-19, 2017.

5. Stoffel EM and Yurgelun MB: Genetic predisposition to colorectal cancer: Implications for treatment and prevention. Semin Oncol 43: 536-542, 2016.

6. Carethers JM and Jung BH: Genetics and genetic biomarkers in sporadic colorectal cancer. Gastroenterology 149: 1177-1190 e1173, 2015

7. Bignucolo A, De Mattia E, Cecchin E, Roncato R and Toffoli G: Pharmacogenomics of targeted agents for personalization of colorectal cancer treatment. Int J Mol Sci 18: pii: E1522, 2017,

8. DeStefanis RA, Kratz JD, Emmerich PB and Deming DA: Targeted therapy in metastatic colorectal cancer: Current standards and novel agents in review. Curr Colorectal Cancer Rep 15: 61-69, 2019.

9. Wakai T, Prasoon P, Hirose Y, Shimada Y, Ichikawa H and Nagahashi M: Next-generation sequencing-based clinical sequencing: Toward precision medicine in solid tumors. Int J Clin Oncol 24: 115-122, 2019.

10. Zhang L, Chen L, Sah S, Latham GJ, Patel R, Song Q, Koeppen H, Tam R, Schleifman E, Mashhedi $\mathrm{H}$, et al: Profiling cancer gene mutations in clinical formalin-fixed, paraffin-embedded colorectal tumor specimens using targeted next-generation sequencing. Oncologist 19: 336-343, 2014.

11. Del Vecchio F, Mastroiaco V, Di Marco A, Compagnoni C, Capece D, Zazzeroni F, Capalbo C, Alesse E and Tessitore A: Next-generation sequencing: Recent applications to the analysis of colorectal cancer. J Transl Med 15: 246, 2017.

12. Wang Y, Liu H, Hou Y, Zhou X, Liang L, Zhang Z, Shi H, Xu S, $\mathrm{Hu}$ P,Zheng Z, et al: Performance validation of an amplicon-based targeted next-generation sequencing assay and mutation profiling of 648 Chinese colorectal cancer patients. Virchows Arch 472: 959-968, 2018

13. Youssef O, Sarhadi V, Ehsan H, Böhling T, Carpelan-Holmström M, Koskensalo S, Puolakkainen P, Kokkola A and Knuutila S: Gene mutations in stool from gastric and colorectal neoplasia patients by next-generation sequencing. World J Gastroenterol 23: 8291-8299, 2017.

14. Kidess E, Heirich K, Wiggin M, Vysotskaia V, Visser BC, Marziali A, Wiedenmann B, Norton JA, Lee M, Jeffrey SS and Poultsides GA: Mutation profiling of tumor DNA from plasma and tumor tissue of colorectal cancer patients with a novel, high-sensitivity multiplexed mutation detection platform. Oncotarget 6: 2549-2561, 2015.

15. Normanno N, Cervantes A, Ciardiello F, De Luca A and Pinto C: The liquid biopsy in the management of colorectal cancer patients: Current applications and future scenarios. Cancer Treat Rev 70: 1-8, 2018.

16. Cserni G: Nodal staging of colorectal carcinomas and sentinel nodes. J Clin Pathol 56: 327-335, 2003.

17. Yang X, Zhuo M, Ye X, Bai H, Wang Z, Sun Y, Zhao J, An T, Duan J, Wu M and Wang J: Quantification of mutant alleles in circulating tumor DNA can predict survival in lung cancer. Oncotarget 7: 20810-20824, 2016.

18. Zhou Q, Zhang XC, Chen ZH, Yin XL, Yang JJ, Xu CR, Yan HH, Chen HJ, Su J, Zhong WZ, et al: Relative abundance of EGFR mutations predicts benefit from gefitinib treatment for advanced non-small-cell lung cancer. J Clin Oncol 29: 3316-3321, 2011.

19. Jeong JH, Kim J, Hong YS, Kim D, Kim JE, Kim SY, Kim KP, Yoon YK, Kim D, Chun SM, et al: HER2 amplification and cetuximab efficacy in patients with metastatic colorectal cancer harboring wild-type RAS and BRAF. Clin Colorectal Cancer 16: e147-e152, 2017.

20. Lee MS, Helms TL, Feng N, Gay J, Chang QE, Tian F, Wu JY, Toniatti C, Heffernan TP, Powis G, et al: Efficacy of the combination of MEK and CDK4/6 inhibitors in vitro and in vivo in KRAS mutant colorectal cancer models. Oncotarget 7: 39595-39608, 2016.

21. Stintzing S, Miller-Phillips L, Modest DP, Fischer von Weikersthal L, Decker T, Kiani A, Vehling-Kaiser U, Al-Batran SE, Heintges T, Kahl C, et al: Impact of BRAF and RAS mutations on first-line efficacy of FOLFIRI plus cetuximab versus FOLFIRI plus bevacizumab: Analysis of the FIRE-3 (AIO KRK-0306) study. Eur J Cancer 79: 50-60, 2017.

22. Wang X, Wei Q, Gao J, Li J, Li J, Gong J, Li Y and Shen L: Clinicopathologic features and treatment efficacy of Chinese patients with BRAF-mutated metastatic colorectal cancer: A retrospective observational study. Chin J Cancer 36: 81, 2017. 
23. Fontanges Q, De Mendonca R, Salmon I, Le Mercier M and D'Haene N: Clinical application of targeted next generation sequencing for colorectal cancers. Int J Mol Sci 17: pii: E2117, 2016.

24. Benson AB III, Venook AP, Cederquist L, Chan E, Chen YJ, Cooper HS, Deming D, Engstrom PF, Enzinger PC, Fichera A, et al: Colon cancer, version 1.2017, NCCN clinical practice guidelines in oncology. J Natl Compr Canc Netw 15: 370-398, 2017.

25. Sepulveda AR, Hamilton SR, Allegra CJ, Grody W, Cushman-Vokoun AM, Funkhouser WK, Kopetz SE, Lieu C, Lindor NM, Minsky BD, et al: Molecular biomarkers for the evaluation of colorectal cancer: Guideline from the American Society for Clinical Pathology, College of American Pathologists, Association for Molecular Pathology, and American Society of Clinical Oncology. J Mol Diagn 19: 187-225, 2017.

26. Corcoran RB, Atreya CE, Falchook GS, Kwak EL, Ryan DP, Bendell JC, Hamid O, Messersmith WA, Daud A, Kurzrock R, et al: Combined BRAF and MEK inhibition with dabrafenib and trametinib in BRAF V600-mutant colorectal cancer. J Clin Oncol 33: 4023-4031, 2015.

27. Fernandes MS, Sanches JM and Seruca R: Targeting the PI3K signalling as a therapeutic strategy in colorectal cancer. Adv Exp Med Biol 1110: 35-53, 2018.

28. Dhillon S: Regorafenib: A review in metastatic colorectal cancer. Drugs 78: 1133-1144, 2018

29. Xue WS, Men SY, Liu W and Liu RH: A meta-analysis of safety and efficacy of regorafenib for refractory metastatic colorectal cancer. Medicine (Baltimore) 97: e12635, 2018.

30. Aprile G, Macerelli M and Giuliani F: Regorafenib for gastrointestinal malignancies: From preclinical data to clinical results of a novel multi-target inhibitor. BioDrugs 27: 213-224, 2013.

31. Krishnaswamy S, Kanteti R, Duke-Cohan JS, Loganathan S, Liu W, Ma PC, Sattler M, Singleton PA, Ramnath N, Innocenti F, et al: Ethnic differences and functional analysis of MET mutations in lung cancer. Clin Cancer Res 15: 5714-5723, 2009.

32. Bradley CA, Salto-Tellez M, Laurent-Puig P, Bardelli A, Rolfo C, Tabernero J, Khawaja HA, Lawler M, Johnston PG, Van Schaeybroeck S and MErCuRIC consortium: Targeting c-MET in gastrointestinal tumours: Rationale, opportunities and challenges. Nat Rev Clin Oncol 14: 562-576, 2017.

33. Pietrantonio F, Oddo D, Gloghini A, Valtorta E, Berenato $\mathrm{R}$ Barault L, Caporale M, Busico A, Morano F, Gualeni AV, et al: MET-driven resistance to dual EGFR and BRAF blockade may be overcome by switching from EGFR to MET inhibition in BRAF-mutated colorectal cancer. Cancer Discov 6: 963-971, 2016

34. DiNardo CD, Stein EM, de Botton S, Roboz GJ, Altman JK, Mims AS, Swords R, Collins RH, Mannis GN, Pollyea DA, et al: Durable remissions with ivosidenib in IDH1-mutated relapsed or refractory AML. N Engl J Med 378: 2386-2398, 2018.

35. Kloth M, Ruesseler V, Engel C, Koenig K, Peifer M, Mariotti E, Kuenstlinger H, Florin A, Rommerscheidt-Fuss U, Koitzsch U, et al: Activating ERBB2/HER2 mutations indicate susceptibility to pan-HER inhibitors in Lynch and Lynch-like colorectal cancer. Gut 65: 1296-1305, 2016.

36. Soussi T and Wiman KG: Shaping genetic alterations in human cancer: The p53 mutation paradigm. Cancer Cell 12: 303-312, 2007.

37. Blandino G and Di Agostino S: New therapeutic strategies to treat human cancers expressing mutant p53 proteins. J Exp Clin Cancer Res 37: 30, 2018.
38. Li XL, Zhou J, Chan ZL, Chooi JY, Chen ZR and Chng WJ: PRIMA-1met (APR-246) inhibits growth of colorectal cancer cells with different p53 status through distinct mechanisms. Oncotarget 6: 36689-36699, 2015.

39. Katoh M and Katoh M: Molecular genetics and targeted therapy of WNT-related human diseases (Review). Int J Mol Med 40: 587-606, 2017.

40. Pearlman R, Frankel WL, Swanson B, Zhao W, Yilmaz A, Miller K, Bacher J, Bigley C, Nelsen L, Goodfellow PJ, et al: Prevalence and spectrum of germline cancer susceptibility gene mutations among patients with early-onset colorectal cancer. JAMA Oncol 3: 464-471, 2017.

41. Yurgelun MB, Kulke MH, Fuchs CS, Allen BA, Uno $\mathrm{H}$, Hornick JL, Ukaegbu CI, Brais LK, McNamara PG, Mayer RJ, et al: Cancer susceptibility gene mutations in individuals with colorectal cancer. J Clin Oncol 35: 1086-1095, 2017.

42. Kato S, Schwaederle M, Daniels GA, Piccioni D, Kesari S, Bazhenova L, Shimabukuro K, Parker BA, Fanta P and Kurzrock R: Cyclin-dependent kinase pathway aberrations in diverse malignancies: Clinical and molecular characteristics. Cell Cycle 14: 1252-1259, 2015.

43. Finn RS, Crown JP, Lang I, Boer K, Bondarenko IM, Kulyk SO, Ettl J, Patel R, Pinter T, Schmidt M, et al: The cyclin-dependent kinase 4/6 inhibitor palbociclib in combination with letrozole versus letrozole alone as first-line treatment of oestrogen receptor-positive, HER2-negative, advanced breast cancer (PALOMA-1/TRIO-18): A randomised phase 2 study. Lancet Oncol 16: 25-35, 2015.

44. Patnaik A, Rosen LS, Tolaney SM, Tolcher AW, Goldman JW, Gandhi L, Papadopoulos KP, Beeram M, Rasco DW, Hilton JF, et al: Efficacy and safety of abemaciclib, an inhibitor of CDK4 and CDK6, for patients with breast cancer, non-small cell lung cancer, and other solid tumors. Cancer Discov 6: 740-753, 2016.

45. Korphaisarn K, Morris VK, Overman MJ, Fogelman DR, Kee BK, Raghav KPS, Manuel S, Shureiqi I, Wolff RA, Eng $\mathrm{C}$, et al: FBXW7 missense mutation: A novel negative prognostic factor in metastatic colorectal adenocarcinoma. Oncotarget 8: 39268-39279, 2017.

46. Lorans M, Dow E, Macrae FA, Winship IM and Buchanan DD: Update on hereditary colorectal cancer: Improving the clinical utility of multigene panel testing. Clin Colorectal Cancer 17: e293-e305, 2018

47. Ma H, Brosens LAA, Offerhaus GJA, Giardiello FM, de Leng WWJ and Montgomery EA: Pathology and genetics of hereditary colorectal cancer. Pathology 50: 49-59, 2018.

48. Lindor NM, McMaster ML, Lindor CJ and Greene MH; National Cancer Institute, Division of Cancer Prevention, Community Oncology and Prevention Trials Research Group: Concise handbook of familial cancer susceptibility syndromes-second edition. J Natl Cancer Inst Monogr: 1-93, 2008.

49. Dudley JC, Lin MT, Le DT and Eshleman JR: Microsatellite instability as a biomarker for PD-1 blockade. Clin Cancer Res 22: 813-820, 2016

50. Ryan E, Sheahan K, Creavin B, Mohan HM and Winter DC: The current value of determining the mismatch repair status of colorectal cancer: A rationale for routine testing. Crit Rev Oncol Hematol 116: 38-57, 2017. 